\title{
Healthcare-associated infections (HAl) research in Asian countries: a bibliometric analysis
}

Cahyadin', Ahmad Watsiq Maula², Anis Fuad²

${ }^{1}$ Field Epidemiology Training Program, Graduate Program of Public Health, Faculty of Medicine, Universitas Gadjah Mada, ${ }^{2}$ Department of Biostatistics, Epidemiology and Population Health, Faculty of Medicine, Universitas Gadjah Mada

DOI: http://dx.doi.org/10.19106/JMedScieSup005001201801

\section{ABSTRACT}

Health care-associated infections ( $\mathrm{HAI})$ are the most frequent adverse event in health-care delivery worldwide, including in Asian countries. Asian countries produced $4,819 \mathrm{HAl}$ publications. Majority of the publications (68\%) appeared in the last decade. The average annual growth rate was $14.8 \%$. Japan was the most productive country that contributes about $13.5 \%$ of total publications, followed by China $(11.7 \%)$, and Taiwan (11.6\%). Asian HAI research were cited in 76,737 articles with an average of 15.9 citations per publication. The top two most highly cited articles were published in the New England Journal of Medicine followed by the Journal of Clinical Microbiology. The top three productive journals were Journal of Hospital Infection (309 papers; 6.4\%), American Journal of Infection Control (198 papers; 4.1\%), and Infection Control and Hospital Epidemiology (170 papers; 3.5\%). The ten top journals contained $25 \%$ of the HAl literatures. Emerging research topics in the last years include ventilator-associated pneumonia, MRSA (methicillin-resistant staphylococcus aureus), acinetobacter baumannii, carbapenems, Republic Korea, and tertiary care center.

Keyword: healthcare-associated infections (HAI) - bibliometrics - Pubmed - Asia 